\title{
Effectiveness of a Combined Dance and Relaxation Intervention on Reducing Anxiety and Depression and Improving Quality of Life among the Cognitively Impaired Elderly
}

"Dina Adam, ${ }^{1,2}$ Ayiesah Ramli, ${ }^{1}$ Suzana Shahar ${ }^{3}$

$$
\begin{aligned}
& \text { فعالية الجمع بين الرقص والاسترخاء في الحد من القلق والاكتئاب وتحسين نوعية } \\
& \text { الحياة بين مرضى الضعف الإدراكي في المسنين }
\end{aligned}
$$

$$
\text { دينا آدم، أيسة رملي، سوزانا شاهـار }
$$

ABSTRACT: Objectives: Cognitive impairment is a common problem among the elderly and is believed to be a precursor to dementia. This study aimed to explore the effectiveness of a combined dance and relaxation intervention as compared to relaxation alone in reducing anxiety and depression levels and improving quality of life (QOL) and cognitive function among the cognitively impaired elderly. Methods: This quasi-experimental study was conducted between May and December 2013 in Peninsular Malaysia. Subjects from four government residential homes for older adults aged $\geq 60$ years with mild to moderate cognitive function as assessed by the Mini-Mental State Examination were included in the study. Subjects were divided into an intervention group and a control group; the former participated in a combined poco-poco dance and relaxation intervention whilst the latter participated in relaxation exercises only. Both groups participated in two sessions per week for six weeks. Anxiety and depression were self-assessed using the Hospital Anxiety and Depression Scale and QOL was self-assessed using the Quality of Life in Alzheimer's Disease questionnaire. Results: A total of 84 elderly subjects were included in the study; 44 were in the intervention group and 40 were in the control group. When compared to control subjects, those in the intervention group showed significantly decreased anxiety $(P<0.001)$ and depression $(P<0.001)$ levels as well as improved QOL $(P<0.001)$ and cognitive impairment $(P<0.001)$. Conclusion: Dance as a form of participationbased physical exercise was found to reduce anxiety and depression levels and improve QOL and cognitive function among the studied sample of cognitively impaired elderly subjects in Malaysia.

Keywords: Mild Cognitive Impairment; Dance Therapy; Quality of Life; Anxiety; Depression; Malaysia

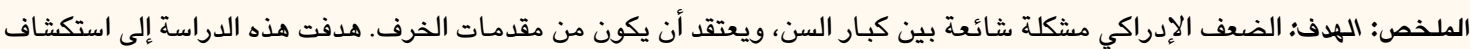

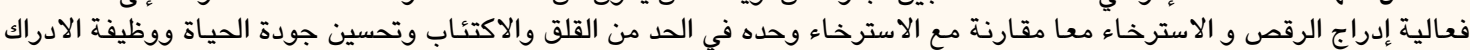

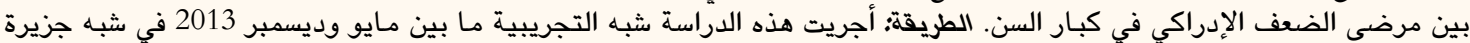

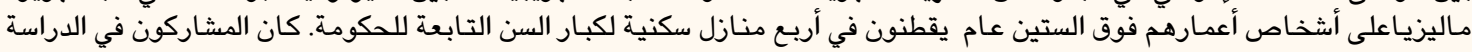

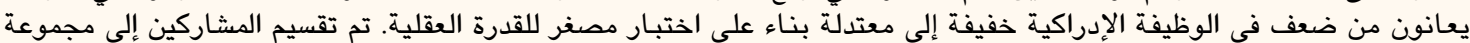

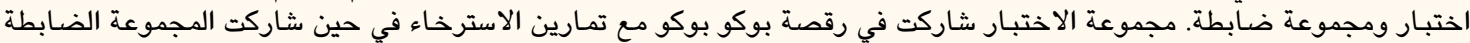

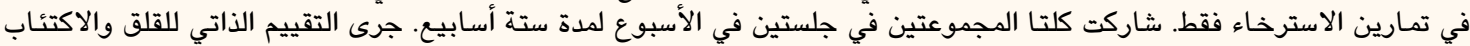

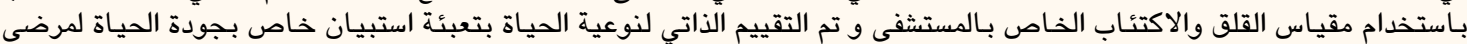

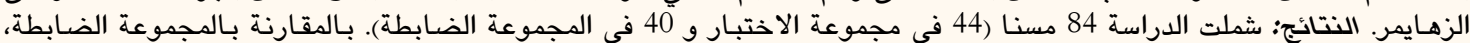

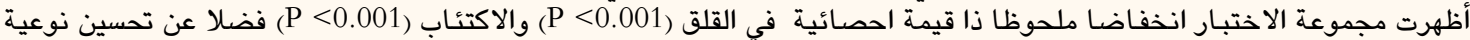

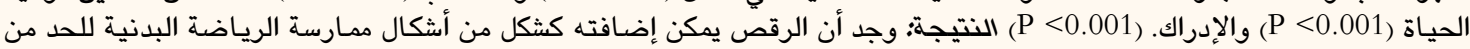

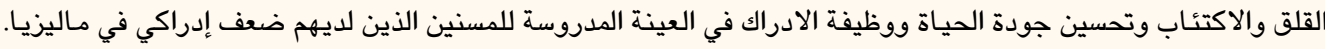

$$
\text { مفتاح الكلمات: الضعف الإدراكي المعتدل؛ العلاج بالرقص؛ جودة الحياة؛ القلق؛ الاكتئاب؛ ماليزيا. }
$$

\section{ADVANCES IN KNOWLEDGE}

The results of the current study indicate that a combination of dance and relaxation exercises improves quality of life (QOL) and cognitive impairment and reduces anxiety and depression among cognitively impaired elderly residents of government institutions as compared to relaxation alone.

\section{Application to Patient Care}

Combined dance and relaxation interventions are recommended for elderly individuals as a form of enjoyable physical activity which can improve cognitive function and QOL and reduce anxiety and depression. 
$\mathrm{M}$ ILD COGNITIVE IMPAIRMENT OCCURS ON a spectrum between normal ageing processes and the development of dementia. ${ }^{1}$ The deterioration of cognitive function is more predominant in anxious or depressed individuals. ${ }^{2}$ According to Nikmat et al., delays in the early detection of cognitive impairment can lead to depression, functional dependence and poor quality of life (QOL). ${ }^{3}$ Decreased physical activity can contribute significantly to increased levels of depression. ${ }^{4}$ Physically active individuals have demonstrated less cognitive decline than sedentary subjects, as well as improved cardiovascular fitness, muscle strength, range of motion, posture, balance and mental health. ${ }^{5,6}$ More than one in six residents of homes for older adults have anxiety and depression problems. ${ }^{7}$ This is likely due to the lack of a supportive environment, societal stigma, depersonalisation, sleep disturbances, communication problems and illnesses that affect their QOL and functional abilities. ${ }^{\text {? }}$

Dance interventions, multi-modal training and progressive muscle relaxation therapy have been identified as measures that can significantly reduce anxiety and depression levels and improve QOL in older adults. ${ }^{5,8,9}$ Dance as a form of physical activity can be performed in a range of environments. ${ }^{10}$ It is safe and more likely to be adopted by older adults as part of their lifestyle compared to other more structured and/ or expensive exercises. ${ }^{11}$ Dance interventions engage the elderly in everyday life by encouraging enjoyment of the activity and improving their psychosocial QOL. ${ }^{6}$ The therapeutic benefits therefore motivate individuals at all levels of fitness to adhere to the interventions. ${ }^{2}$

Besides dance therapy, relaxation exercises using the imagination method are useful in treating stress and anxiety, especially among older adults. ${ }^{12}$ These exercises are believed to be beneficial in releasing physical and mental stress, decreasing depressive symptoms and enhancing QOL. Many types of relaxation exercises-including breathing techniques, meditation, progressive muscle relaxation and autogenic training-have a positive impact on anxiety. ${ }^{13}$ However, very few studies have investigated the beneficial effects of a combination of dance and relaxation exercises in improving the psychological status of older adults. Therefore, this study aimed to determine the effectiveness of a combined dance and relaxation intervention in reducing anxiety and depression and improving cognitive impairment and QOL among elderly individuals with cognitive impairment residing in publicly-funded institutions.

\section{Methods}

This quasi-experimental study was carried out between May and December 2013 in four government residential homes for older adults in Peninsular Malaysia (Rumah Seri Kenangan Seremban, Negeri Sembilan; Rumah Seri Kenangan Cheras, Klang Valley; Rumah Seri Kenangan Cheng, Melaka; and Rumah Seri Kenangan Taiping, Perak). These institutions represent major publicly-funded institutions in the southern, central and northern areas of Peninsular Malaysia. Subjects between $60-80$ years old who could walk independently and had mild (18/30) to moderate (28/30) cognitive impairment as categorised by the Mini-Mental State Examination (MMSE) were included. ${ }^{14}$ Exclusion criteria included uncontrolled hypertension or terminal illness; severe cognitive and musculoskeletal impairments; cardiovascular disease; mental illness; stroke; administration of antipsychotic or anticholinergic drugs; hearing or vision deterioration; speech disturbances; difficulties in performing daily routines; and severe pain. ${ }^{10}$

Subjects were divided into an intervention group and a control group; the intervention group undertook a combination of poco-poco dance and relaxation exercises whilst the control group participated only in the relaxation exercises. Both groups had sessions twice per week for six weeks resulting in a total of 12 sessions. Dance sessions were facilitated by an experienced physical therapist, with each 60-minute session beginning with 10 minutes of warm-up and stretching activities followed by a 20-minute pocopoco dance session. The dance routine included two sidewalk steps to the right, left and back to the midpoint position repeated twice, followed by three backward steps from the mid-point forwards and then backwards repeated twice before a forward-backward weight transfer in walking stance repeated twice. The whole cycle was then repeated several times. At baseline and during the first two weeks, lower limb movements were incorporated with slow simple reciprocal armswinging. From the third week onwards, the intensity of the limb movements increased to include extension of the arms straight upward and forward-backward arm-swinging three times to both sides. In the fifth and sixth weeks, circular arm motions were added three times to both sides. All dance sessions concluded with a 10-minute cool-down period.

Participants in the intervention group undertook a 30-minute relaxation session following their dance session. In the control group, subjects took part in a 40-minute relaxation session without any physical intervention. In the relaxation sessions, subjects were requested to sit comfortably on a chair in a quiet area and loosen any tight clothing before closing their eyes 
and focusing on slow deep breathing, emphasising their exhalations. Relaxing music was played on a compact disc player and subjects were asked to visualise a peaceful and calming environment. Using the progressive muscle relaxation technique, participants were encouraged to tense and hold certain muscles for five seconds and then relax the muscles for 30 seconds, starting with their foot, calf and thigh, hand and arm, buttocks and stomach muscles and progressing up to their neck and head muscles. ${ }^{15}$ Subjects were then asked to lift their shoulders up to the ears for five seconds before lowering them. For facial muscles, the subjects had to yawn and pout, frown and wrinkle their nose and raise and lower their eyebrows. Finally, subjects had to wriggle their fingers and toes before opening their eyes. This process was carried out three times with deep breathing exercises interspersed throughout each session. ${ }^{16}$

Among the subjects, anxiety, depression and QOL were evaluated at baseline and during the third and sixth week of the intervention. Anxiety and depression were evaluated using the Hospital Anxiety and Depression Scale (HADS), a brief selfadministered questionnaire designed to assess the presence of general anxiety and depression disorders. ${ }^{17,18}$ A score of $<7$ was considered normal, 8-10 borderline abnormal and $\geq 11$ abnormal out of a total score of 21 . QOL was assessed using the Quality of Life in Alzheimer's Disease (QOL-AD) questionnaire. The QOL-AD questionnaire is considered a valid, reliable and appropriate instrument for assessing QOL in individuals with cognitive impairment, particularly as the completion time is relatively short and the completion rate is high. ${ }^{19,20}$ Scores are rated on a 4-point scale, with 1 indicating poor and 4 indicating excellent QOL. Total scores range from 13-52 with higher scores indicating a better QOL. Cognitive impairment was measured at baseline and during the third and sixth weeks using the MMSE.

Statistical analysis was performed using the Statistical Package for the Social Sciences (SPSS), Version 20 (IBM Corp., Chicago, Illinois, USA). Results were expressed as means \pm standard deviations. A repeated-measures analysis of variance (ANOVA) model was used to compare the effects of the interaction (time*group) with anxiety and depression levels and QOL-AD scores at three intervals (at baseline and during the third and sixth week). If the sphericity assumption was not violated ( $P<0.05$ using Mauchly's test of sphericity), the HuynhFeldt correction was used to estimate $P$ values. ${ }^{21}$ Cognitive impairment, anxiety and depression levels and QOL were compared between the two groups at each interval using a repeated-measures ANOVA model with the Bonferroni correction for multiple outcomes. A partial eta-squared statistic $\left(\eta^{2}\right)$ was used to
Table 1: Demographic variables of elderly Malaysian subjects undergoing a combined dance and relaxation intervention as compared to controls undergoing relaxation exercises alone $(\mathrm{N}=84)$

\begin{tabular}{|c|c|c|c|}
\hline \multirow[t]{2}{*}{ Variable } & \multicolumn{2}{|l|}{ n (\%) } & \multirow[t]{2}{*}{$P$ value } \\
\hline & $\begin{array}{l}\text { Control } \\
\text { group } \\
(\mathbf{n}=40)\end{array}$ & $\begin{array}{l}\text { Intervention } \\
\text { group } \\
(\mathbf{n}=44)\end{array}$ & \\
\hline \multicolumn{3}{|c|}{ Cognitive impairment ${ }^{*}$} & 0.185 \\
\hline Mild & $30(75.0)$ & 38 (86.4) & \\
\hline Moderate & $10(25.0)$ & $6(13.6)$ & \\
\hline \multicolumn{3}{|l|}{ Age in years } & 0.287 \\
\hline$>60$ & $21(52.5)$ & $18(40.9)$ & \\
\hline$>70$ & $19(47.5)$ & $26(59.1)$ & \\
\hline \multicolumn{3}{|l|}{ Gender } & 0.662 \\
\hline Male & $21(52.5)$ & $21(47.7)$ & \\
\hline Female & $19(47.5)$ & $23(52.3)$ & \\
\hline \multicolumn{3}{|c|}{ Education level } & 0.693 \\
\hline None & $11(27.5)$ & $9(20.5)$ & \\
\hline Primary & $22(55.0)$ & $25(56.8)$ & \\
\hline $\begin{array}{l}\text { Secondary/ } \\
\text { tertiary }\end{array}$ & $7(17.5)$ & $10(22.7)$ & \\
\hline \multicolumn{3}{|l|}{ Anxiety $^{\dagger}$} & 0.433 \\
\hline $\begin{array}{l}\text { Borderline } \\
\text { abnormal }\end{array}$ & $33(82.5)$ & $32(72.7)$ & \\
\hline Abnormal & $7(17.5)$ & $12(27.3)$ & \\
\hline \multicolumn{3}{|l|}{ Depression $^{\dagger}$} & 0.073 \\
\hline $\begin{array}{l}\text { Borderline } \\
\text { abnormal }\end{array}$ & $32(80.0)$ & $36(81.8)$ & \\
\hline Abnormal & $8(20.0)$ & $8(18.2)$ & \\
\hline \multicolumn{3}{|l|}{$\mathrm{QOL}^{\ddagger}$} & 0.915 \\
\hline Low & $25(62.5)$ & $27(61.4)$ & \\
\hline High & $15(37.5)$ & $17(38.6)$ & \\
\hline \multicolumn{4}{|c|}{$Q O L=$ quality of life. } \\
\hline \multicolumn{4}{|c|}{$\begin{array}{l}\text { "Cognitive impairment was assessed using the Mini-Mental State } \\
\text { Examination with scores of } 21-28 \text { and } 10-20 \text { out of } 30 \text { indicating } \\
\text { mild and moderate cognitive impairment, respectively. }{ }^{14} \text { Anxiety and } \\
\text { depression were self-assessed using the Hospital Anxiety and Depression } \\
\text { Scale with scores of }<7,8-10 \text { and } \geq 11 \text { out of } 21 \text { considered normal, } \\
\text { borderline abnormal and abnormal, respectively.1,18 }{ }^{17} Q O L \text { was self- } \\
\text { assessed using the Quality of Life in Alzheimer's Disease questionnaire } \\
\text { with scores of }<33 \text { and }>34 \text { out of } 52 \text { indicating low and high QOL, } \\
\text { respectively. }{ }^{1,20}\end{array}$} \\
\hline
\end{tabular}

measure the effect size as either small $\left(0.01 \leq \eta^{2}<0.06\right)$, medium $\left(0.06 \leq \eta^{2}<0.14\right)$ or large $\left(\eta^{2} \geq 0.14\right)$. ${ }^{22}$ The level of statistical significance was set at $P<0.050$.

This study was approved by the Researchers Ethics Committee at Universiti Kebangsaan Malaysia, Bangi, Malaysia (\#UKM1.5.3.5/244/NN-086-2013). Informed consent was obtained from all of the subjects prior to their participation in the intervention. 
Table 2: Comparison of variables among elderly Malaysian subjects undergoing a combined dance and relaxation intervention $(n=44)$ as compared to controls $(\mathrm{n}=40)$ undergoing relaxation exercises alone $(\mathrm{N}=84)$

\begin{tabular}{|c|c|c|c|c|c|}
\hline \multirow[t]{2}{*}{ Variable } & \multicolumn{3}{|c|}{ Mean \pm SD } & \multirow{2}{*}{$\begin{array}{c}P \\
\text { value }\end{array}$} & \multirow{2}{*}{$\begin{array}{c}\text { Partial } \\
\eta^{2 * *}\end{array}$} \\
\hline & Baseline & Week 3 & Week 6 & & \\
\hline \multicolumn{4}{|c|}{ Cognitive impairment ${ }^{\dagger}$} & $<0.001$ & 0.42 \\
\hline IG & $23.7 \pm 3.4$ & $25.0 \pm 3.3$ & $26.6 \pm 3.0$ & & \\
\hline CG & $22.6 \pm 3.2$ & $22.5 \pm 3.2$ & $21.2 \pm 3.7$ & & \\
\hline \multicolumn{4}{|l|}{ Anxiety $^{\ddagger}$} & $<0.001$ & 0.26 \\
\hline IG & $7.5 \pm 3.5$ & $6.1 \pm 3.6$ & $4.4 \pm 2.7$ & & \\
\hline CG & $6.2 \pm 3.7$ & $7.1 \pm 3.3$ & $7.6 \pm 3.1$ & & \\
\hline \multicolumn{4}{|c|}{ Depression $^{\ddagger}$} & $<0.001$ & 0.35 \\
\hline IG & $7.6 \pm 3.1$ & $5.3 \pm 3.0$ & $3.7 \pm 2.7$ & & \\
\hline CG & $7.1 \pm 3.1$ & $8.1 \pm 3.3$ & $8.4 \pm 3.4$ & & \\
\hline \multicolumn{4}{|l|}{$\mathrm{QOL}^{\S}$} & $<0.001$ & 0.29 \\
\hline IG & $32.0 \pm 7.0$ & $34.1 \pm 5.1$ & $36.4 \pm 4.1$ & & \\
\hline CG & $31.6 \pm 4.8$ & $30.2 \pm 4.6$ & $28.8 \pm 4.4$ & & \\
\hline
\end{tabular}

$S D=$ standard deviation; $I G=$ intervention group; $C G=$ control group; $Q O L=$ quality of life.

*Partial $\eta^{2}$ was used to measure the effect size as either small $\left(0.01 \leq \eta^{2}<0.06\right)$, medium $\left(0.06 \leq \eta^{2}<0.14\right)$ or large $\left(\eta^{2} \geq 0.14\right) .{ }^{22}{ }^{\dagger}$ Cognitive impairment was assessed using the Mini-Mental State Examination with scores of 21-28 and 10-20 out of 30 indicating mild and moderate cognitive impairment, respectively. ${ }^{14}{ }^{7}$ Anxiety and depression were self-assessed using the Hospital Anxiety and Depression Scale with scores of $<7,8-10$ and $\geq 11$ out of 21 considered normal, borderline abnormal and abnormal, respectively. $17,18{ }^{\$} \mathrm{QOL}$ was self-assessed by subjects using the Quality of Life in Alzheimer's Disease questionnaire with scores of $<33$ and $>34$ out of 52 indicating low and high $Q O L$, respectively. ${ }^{19,20}$

\section{Results}

A total of 84 subjects were included in the study and were divided into an intervention group $(n=44)$ and control group $(n=40)$. The mean age of the subjects was $70.87 \pm 8.19$ years. At baseline, there were no significant differences in cognitive impairment, age, gender or education level between the groups $(P$ $>0.050$ ). However, a lower percentage of subjects in the intervention group had moderate cognitive impairment as compared to the control group $(13.6 \%$ versus $25.0 \% ; P>0.050$ ) [Table 1 ]

There was a significant interaction between time interval and group for cognitive impairment $(P<0.001)$, anxiety $(P<0.001)$, depression $(P<0.001)$ and QOL $(P<0.001)$, with subjects in the intervention group showing improved cognitive impairment, reduced anxiety and depression levels and improved QOL. This represented a large effect $\left(\right.$ partial $\eta^{2}=0.42,0.26,0.35$ and 0.29 , respectively) [Table 2]. Furthermore, a significant difference was noted between the third and sixth week of the intervention for all of the subjects, regardless of group, for cognitive impairment $(P<0.001)$, anxiety $(P<0.001)$, depression $(P<0.001)$ and QOL $(P<0.001)$ [Table 3].

At baseline, there were equal rates of borderline abnormal anxiety $(22.7 \% ; \mathrm{n}=10)$ and abnormal anxiety $(22.7 \% ; n=10)$ in the intervention group. At the same time interval, rates of borderline abnormal depression and abnormal depression in the intervention group were $34.1 \%(n=7)$ and $18.2 \%(n=8)$, respectively. A drastic improvement was observed following six weeks of the intervention, with the majority of subjects in the intervention group reporting normal anxiety levels $(90.9 \% ; n=40)$ and only $6.8 \%(n=3)$ reporting borderline abnormal anxiety. A similar trend was observed for depression, with 95.5\% $(n=42)$ of subjects in the intervention group reporting normal depression levels after six weeks of the intervention; in contrast, only $57.5 \%(\mathrm{n}=23)$ and $37.5 \%(\mathrm{n}=15)$ of those in the control group reported normal anxiety and normal depression levels by the sixth week [Figure 1]

Table 3: Comparison of cognitive impairment, anxiety, depression and quality of life according to time interval among elderly Malaysian subjects $(\mathrm{N}=84)$

\begin{tabular}{|c|c|c|c|c|c|c|c|c|}
\hline \multirow[t]{2}{*}{ Interval } & \multicolumn{2}{|c|}{ Cognitive impairment* } & \multicolumn{2}{|c|}{ Anxiety $^{\dagger}$} & \multicolumn{2}{|c|}{ Depression $^{\dagger}$} & \multicolumn{2}{|c|}{$\mathbf{Q O L}^{\neq}$} \\
\hline & $\begin{array}{c}\text { Mean } \\
(95 \% \text { CI })\end{array}$ & $P$ value $^{\S}$ & $\begin{array}{c}\text { Mean } \\
(95 \% \text { CI })\end{array}$ & $P$ value ${ }^{\S}$ & $\begin{array}{c}\text { Mean } \\
(95 \% \mathrm{CI})\end{array}$ & $P$ value ${ }^{\S}$ & $\begin{array}{c}\text { Mean } \\
(95 \% \text { CI })\end{array}$ & $P$ value $^{\S}$ \\
\hline Baseline & $\begin{array}{c}23.5 \\
(22.8-24.1)\end{array}$ & $<0.001$ & $\begin{array}{c}6.7 \\
(6.0-7.4)\end{array}$ & $<0.001$ & $\begin{array}{c}7.0 \\
(6.4-7.6)\end{array}$ & $<0.001$ & $\begin{array}{c}32.0 \\
(30.9-33.0)\end{array}$ & $<0.001$ \\
\hline Week 3 & $\begin{array}{c}23.8 \\
(23.1-24.5)\end{array}$ & $<0.001$ & $\begin{array}{c}6.3 \\
(5.7-6.9)\end{array}$ & $<0.001$ & $\begin{array}{c}6.4 \\
(5.7-7.0)\end{array}$ & $<0.001$ & $\begin{array}{c}32.4 \\
(31.4-33.3)\end{array}$ & $<0.001$ \\
\hline Week 6 & $\begin{array}{c}23.5 \\
(22.8-24.2)\end{array}$ & $<0.001$ & $\begin{array}{c}6.4 \\
(5.8-7.0)\end{array}$ & $<0.001$ & $\begin{array}{c}6.7 \\
(6.1-7.3)\end{array}$ & $<0.001$ & $\begin{array}{c}32.2 \\
(31.2-33.2)\end{array}$ & $<0.001$ \\
\hline
\end{tabular}

$Q O L=$ quality of life; $C I=$ confidence interval .

*Cognitive impairment was assessed using the Mini-Mental State Examination with scores of 21-28 and 10-20 out of 30 indicating mild and moderate cognitive impairment, respectively. ${ }^{14}{ }^{+}$Anxiety and depression were self-assessed using the Hospital Anxiety and Depression Scale with scores of $<7,8-10$ and $\geq 11$ out of 21 considered normal, borderline abnormal and abnormal, respectively. ${ }^{17,18}{ }^{*} Q O L$ was self-assessed using the Quality of Life in Alzheimer's Disease questionnaire with scores of $<33$ and $>34$ out of 52 indicating low and high QOL, respectively. $19,20 \$ P$ values were adjusted for multiple comparisons using the Bonferroni correction procedure. 


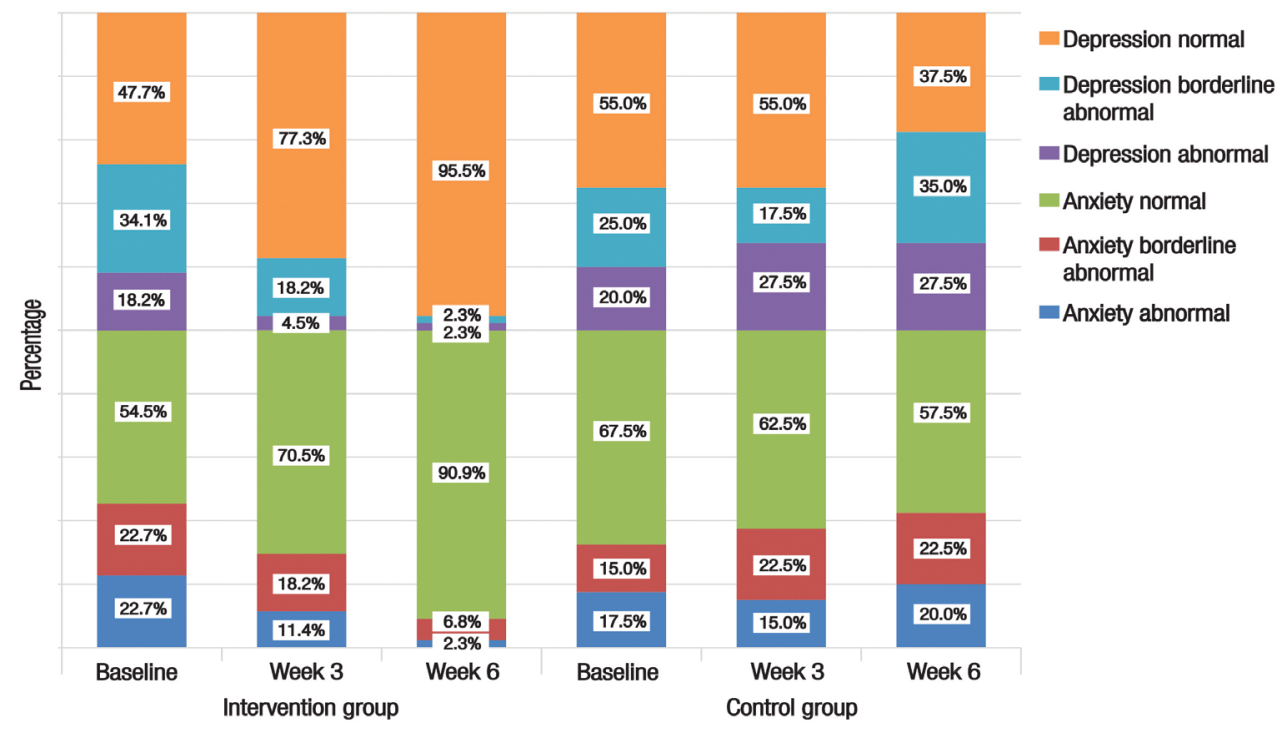

Figure 1: Anxiety and depression levels according to time interval among elderly Malaysian subjects undergoing a combined dance and relaxation intervention $(n=44)$ as compared to control subjects $(n=40)$ undergoing relaxation exercises alone $(\mathrm{N}=84)$. Anxiety and depression were self-assessed using the Hospital Anxiety and Depression Scale with scores of $<7,8-10$ and $\geq 11$ out of 21 considered normal, borderline abnormal and abnormal, respectively. ${ }^{17,18}$ Subjects were evaluated at baseline and during the third and sixth week of the intervention.

Slightly fewer subjects in the intervention group re-ported low baseline QOL scores compared to those in the control group (61.4\% versus $62.5 \%$; $\mathrm{n}=27$ versus 25). However, during the sixth week, $81.8 \%$ $(n=36)$ of those in the intervention group reported high QOL scores. In comparison, 87.5\% $(\mathrm{n}=35)$ of those in the control group reported low QOL scores during the sixth week with only $12.5 \%(n=5)$ reporting high QOL scores [Figure 2].

\section{Discussion}

In the current study, the combined dance and relaxation intervention was found to significantly improve cognition and QOL and decrease anxiety and depression symptoms among elderly Malaysian subjects. Additionally, the large effect size supported the magnitude of the findings. This was consistent with a pilot study which demonstrated that music therapy and physical relaxation were beneficial in improving physical and mental function. ${ }^{23}$ The duration of the six-week intervention period was chosen to minimise

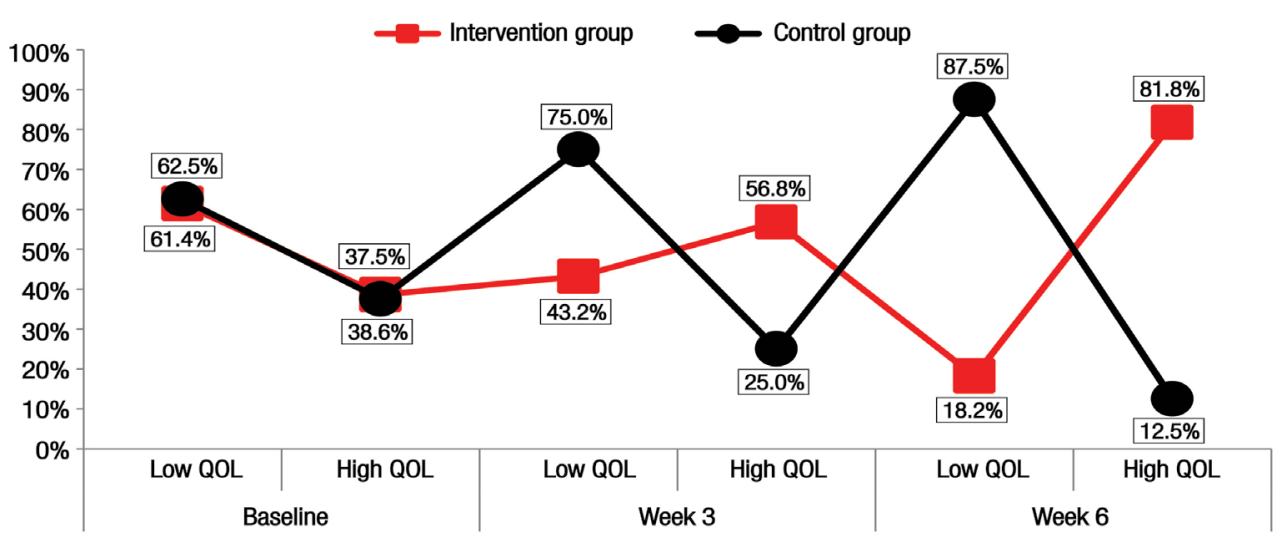

Figure 2: Quality of life (QOL) according to time interval among elderly Malaysian subjects undergoing a combined dance and relaxation intervention $(n=44)$ as compared to control subjects $(n=40)$ undergoing relaxation exercises alone $(\mathrm{N}=84)$. QOL was self-assessed using the Quality of Life in Alzheimer's Disease questionnaire with scores of $<33$ and $>34$ out of 52 indicating low and high QOL, respectively. ${ }^{19,20}$ Subjects were evaluated at baseline and during the third and sixth week of the intervention. 
drop-outs among the studied sample, particularly considering potential health problems among the participants. Gottlieb et al. found that a shorter intervention period could still have significant effects while also encouraging adherence. ${ }^{24}$

As a result of the six-week intervention, participants in the intervention group in the current study experienced improvements in cognitive impairment, anxiety, depression and QOL as measured by MMSE, HADS and QOL-AD scores, respectively. The intensity of the dance activities increased progressively in order to encourage balance, focus and engagement with the activities, with simple reciprocal arm swings progressing to forward and backward arm movements which were then later augmented with circular motions. Gradually increasing the intensity and biomechanical movements within dance sessions may further improve aspects of cognitive function, balance and QOL. ${ }^{25}$ Listening to music and dancing stimulates the parietal lobe and provides somatosensory input; these may increase the neurotrophic factor that improves cognitive and visuospatial function. ${ }^{26}$ Pocopoco is a commonly enjoyed dance among the local population of Malaysia. ${ }^{27}$ Subjects taking part in pocopoco dance sessions may favour this type of dance because it is non-competitive.

Anxiety and depression levels among control subjects in the current study were slightly lower during the third week compared to the sixth week. The leading factor contributing to depression is a perceived lack of control in life; other possible contributors include a lack of harmony with the surrounding environment, limited physical ability and various family, social and economic issues. ${ }^{8,28}$ Gottlieb et al. found that females had higher rates of borderline abnormal anxiety levels and depression compared to males; however, they also demonstrated greater improvement than their male counterparts. ${ }^{24}$ This may have been because they were more naturally inclined to enjoy dance-like activities. ${ }^{24}$ In the current study, anxiety and depression levels were reduced among the intervention group and higher among the control group; these findings were consistent with previous studies. ${ }^{23,29}$

Relaxation therapy alone without the physical movements encouraged by the dance intervention was not as effective in decreasing anxiety or depression among studied participants with a low quality of life. On the other hand, those undergoing a combined dance and relaxation intervention had reduced levels of anxiety and depression regardless of quality of life. Relaxation therapy alone may more effectively reduce anxiety and depression symptoms if sessions are conducted more frequently (i.e. if the participants engage in at least 50 sessions). ${ }^{17}$ The effect of relaxation therapy is generally minimal among elderly residents receiving standard care in institutions..$^{30}$ In Malaysia, government policies ensure that elderly residents receive continuous support and care to prevent loss of functionality. ${ }^{25}$ Older adults in institutions therefore have ample and equal opportunities to take part in institutional activities. ${ }^{25}$

The significant improvement in cognitive function observed among subjects in the intervention group in the current study was consistent with the findings of Middleton et al. ${ }^{6}$ Improvements in QOL following physical interventions such as dance are potentially related to increased cognitive and physical function as well as an enhanced sense of wellbeing. ${ }^{8}$ These factors may also be linked with enhanced coping strategies when facing difficult situations within the residence and an increased sense of independence. ${ }^{31}$

This study has several limitations. As the subjects were neither randomised nor blinded, it is possible that those who agreed to participate may have been more motivated to engage in the intervention. Additionally, the study was limited by the small sample size, the absence of a no-treatment control group and the heterogeneity of the groups. Further studies to evaluate the effects of exercise intensity, frequency and duration on cognitive function are needed to verify the improvements observed in the present study. Despite these limitations, the findings of this study provide evidence of the positive effects of dance exercise on cognitive status among elderly people. Dance interventions should therefore be encouraged as an enjoyable and beneficial leisure activity in institutions for elderly residents. Such interventions should be conducted on a larger scale for longer periods of time.

\section{Conclusion}

Participation in a six-week combined dance and relaxation intervention was found to significantly reduce anxiety and depression levels and improve cognitive function and QOL among studied elderly Malaysian subjects. Furthermore, significant improvement in QOL were reported by the participants during the third week of the intervention, after only six dance and relaxation sessions. Dance interventions are therefore recommended for elderly residents among government institutions as a method of improving mental health and QOL.

\section{CONFLICT OF INTEREST}

The authors declare no conflicts of interest. 


\section{References}

1. Petersen RC. Mild cognitive impairment as a diagnostic entity J Int Med 2004; 256:183-94. doi: 10.1111/j.1365-2796.2004. 01388.x.

2. Jorm AF, Christensen H, Korten AE, Henderson AS, Jacomb PA, Mackinnon A. Do cognitive complaints either predict future cognitive decline or reflect past cognitive decline? A longitudinal study of an elderly community sample. Psycho Med 1997; 27:91-8.

3. Nikmat AW, Hawthorne G, Al-Mashoor SH. Dementia in Malaysia: Issues and challenges. ASEAN J Psychiatr 2011 12:95-101.

4. Vanková $\mathrm{H}$, Holmerová I, Andel $\mathrm{R}$, Veleta P, Janecková $\mathrm{H}$. Functional status and depressive symptoms among older adults from residential care facilities in the Czech Republic. Int Geriatr Psychiatry 2008; 23:466-71. doi: 10.1002/gps.1905.

5. Douglas S, James I, Ballard C. Non-pharmacological interventions in dementia. Adv Psychiatr Treat 2004; 10:171-7. doi: 10.1192/apt.10.3.171.

6. Middleton LE, Yaffe K. Promising strategies for the prevention of dementia. Arch Neurol 2009; 66:1210-15. doi: 10.1001/ archneurol.2009.201.

7. Reynolds CF 3rd, Frank E, Perel JM, Imber SD, Cornes C Miller MD, et al. Nortriptyline and interpersonal psychotherapy as maintenance therapies for recurrent major depression: A randomized controlled trial in patients older than 59 years. JAMA 1999; 281:39-45. doi: 10.1001/jama.281.1.39.

8. de Silva Borges EG, de Souza Vale RG, Cader SA, Leal S Miguel F, Pernambuco CS, et al. Postural balance and falls in elderly nursing home residents enrolled in a ballroom dancing program. Arch Gerontol Geriatr 2014; 59:312-16. doi: 10.1016/j.archger.2014.03.013

9. Dehdari T, Heidarnia A, Ramezankhani A, Sadeghian S Ghofranipour F. Effects of progressive muscular relaxation training on quality of life in anxious patients after coronary artery bypass graft surgery. Indian J Med Res 2009; 129:603-8.

10. Hauer K, Specht N, Schuler M, Bärtsch P, Oster P. Intensive physical training in geriatric patients after severe falls and hip surgery. Age Ageing 2002; 3:49-57. doi: 10.1093/ageing/31.1.49.

11. Peri K, Kerse N, Robinson E, Parsons M, Parsons J, Latham N Does functionally based activity make a difference to health status and mobility? A randomised controlled trial in residential care facilities (The Promoting Independent Living Study; PILS) Age Ageing 2008; 37:57-63. doi: 10.1093/ageing/afm135.

12. Manzoni GM, Pagnini F, Castelnuovo G, Molinari E. Relaxation training for anxiety: A ten-years systematic review with metaanalysis. BMC Psychiatry 2008; 8:41. doi: 10.1186/1471-244X$8-41$.

13. Malchiodi CA. Handbook of Art Therapy, 1st ed. New York, USA: Guilford Press, 2003. Pp. 5-24.

14. Ibrahim NM, Shohaimi S, Chong HT, Rahman AH, Razali R, Esther E, et al. Validation study of the Mini-Mental State Examination in a Malay-speaking elderly population in Malaysia. Dement Geriat Cogn Disord 2009; 27:247-53. doi: $10.1159 / 000203888$

15. Jacobson E. Progressive relaxation. Am J Psychol 1987; 100:522-37. doi: 10.2307/1422693.
16. Ip-Winfield V, Grocke D. Group music therapy methods in cross-cultural aged care practice in Australia. Aus J Music Ther 2011; 22:59-80.

17. Conrad P. The Medicalization of Society: On the transformation of human conditions into treatable disorders, 1st ed. Baltimore, USA: Johns Hopkins University Press, 2007. Pp. 133-45. doi: 10.1056/NEJMbkrev58828.

18. Zigmond AS, Snaith RP. The hospital anxiety and depression scale. Acta Psychiatr Scand 1983; 67:361-70. doi: 10.1111/ j.1600-0447.1983.tb09716.x.

19. Logsdon RG, Gibbons LE, McCurry SM, Teri L. Assessing quality of life in older adults with cognitive impairment. Psychosom Med 2002; 64:510-19. doi: 10.1097/00006842200205000-00016.

20. Moyle W, Gracia N, Murfield JE, Griffiths SG, Venturato L. Assessing quality of life of older people with dementia in longterm care: A comparison of two self-report measures. J Clin Nurs 2012; 21:1632-40. doi: 10.1111/j.1365-2702.2011.03688.x.

21. Weerahandi S. Generalized Inference in Repeated Measures: Exact methods in MANOVA and mixed models, 1st ed Oxford, UK: Wiley-Interscience, 2004. Pp. 39-88.

22. Cohen J. Statistical Power Analysis for the Behavioral Sciences, 2nd ed. Hillsdale, New Jersey, USA: Routledge, 1988. Pp. 273-88.

23. Castelino A. The effect of single sessions of music therapy on the level of anxiety in older persons with psychiatric disorders: A pilot study. Thesis, 2009, New Zealand School of Music, Wellington, New Zealand.

24. Gottlieb SS, Khatta M, Friedmann E, Einbinder L, Katzen S, Baker B, et al. The influence of age, gender, and race on the prevalence of depression in heart failure patients. J Am Coll Cardiol 2004; 43:1542-9. doi: 10.1016/j.jacc.2003.10.064.

25. Ministry of Women, Family and Community Development. National policy for the elderly. From: www.kpwkm.gov.my/ documents/10156/576479be-3a70-4dc0-82dd-0ee30cc83ea8 Accessed: Jul 2015

26. Cotman CW, Engesser-Cesar C. Exercise enhances and protects brain function. Exerc Sport Sci Rev 2002; 30:75-9. doi: 10.1097/00003677-200204000-00006

27. Khan A, Brown WI, Burton NW. What physical activity contexts do adults with psychological distress prefer? J Sci Med Sport 2013; 16:417-21. doi: 2010.1016/j.jsams.2012.10.007.

28. Pinniger R, Brown RF, Thorsteinsson EB, McKinley P. Argentino tango dance compared to mindfulness meditation and a waitinglist control: A randomised trial for treating depression. Complement Ther Med 2012; 20:377-84. doi: 10.1016/j.ctim. 2012.07.003.

29. Masomeh AT, Mehdi S, Monire MN. The effect of selected relaxation training with physical activity on mental well-being. Ann Biol Res 2012; 3:2893-9.

30. Horgas AL, Yoon SL, Grall M. Pain management. In: Boltz M, Capezuti E, Fulmer T, Zwicker D, Eds. Evidence-Based Geriatric Nursing Protocols for Best Practice, 4th ed. New York, USA: Springer Publishing Company. Pp. 246-67.31.

31. Lagacé M, Tanguay A, Lavallée ML, Laplante J, Robichaud S. The silent impact of ageist communication in long term care facilities: Elders' perspectives on quality of life and coping strategies. J Aging Stud 2012; 26:335-42. doi: 10.1016/j. jaging.2012.03.002 